\title{
PATH ANALYSIS FOR GRAIN YIELD IN BARNYARD MILLET (ECHINOCHLOA FRUMENTACEA (ROXB.) LINK )
}

\author{
R Prakash* and C VanNiarajan \\ Department of Plant Breeding and Genetics, Agricultural College and Research Institute, \\ Tamil Nadu Agricultural University, Madurai-625104, India
}

Key words: Barnyard millet, Path coefficient analysis, Grain yield

\begin{abstract}
Path coefficient analysis was studied in 65 genotypes of barnyard millet to find out the association studies of characters and their direct and indirect effects on grain yield/plant. Results exhibited that single earhead weight had maximum direct effects on grain yield/plant followed by straw yield/plant, earhead length and plant height.
\end{abstract}

Small millets are gaining importance because of their nutritional value and adaptability to drought and varied soil conditions. Realizing the nutraceutical values of small millets, they are now considered as "nutri-cereals". Barnyard millet is one among the small millets which is the fastest growing of all millets and produces a crop in six weeks. It is cultivated mainly for the nutritious grains and the straw has a good fodder value (Gopalan et al. 2002). It has a fair source of protein, which is highly digestible and is an excellent source of dietary fibre with good amounts of soluble and insoluble fractions. The carbohydrate content is low and slowly digestible, which makes the barnyard millet a nature's gift for the modern mankind who is engaged in sedentary activities. Grain yield is a complex polygenic character and is strongly influenced by environmental factors. A detailed knowledge of association between quantitative traits is essential for formulating an effective breeding programme in any crop. Path coefficient analysis permits the separation of the direct effects from the indirect effects through other related characters by partitioning the genotypic correlation coefficients, providing a clear picture of the characters that can be relied upon in a selection programme for improvement of grain yield. So far very limited work has been done for the improvement of barnyard millet crop. Therefore, an attempt has been made in the present study to estimate correlation among the component characters and their direct and indirect contributions through path coefficient analysis.

The trial consisted of 65 indigenous and exotic barnyard millet germplasm accessions were obtained from ICRISAT, Hyderabad and Department of Millets, CPBG, Tamil Nadu Agricultural University, Coimbatore and Department of Plant Breeding and Genetics, Agricultural College and Research Institute, Madurai. The accessions were raised in RBD with three replications at Agricultural College and Research Institute, TNAU, Madurai (Latitude 9 ${ }^{\circ} 54^{\prime} \mathrm{N}$, Longitude 78 $54^{\prime}$ $\mathrm{E}$ and with an annual average rainfall of $856 \mathrm{~mm}$ ) of Tamil Nadu State during rabi, 2012. Each plot consisted of a single row of $3 \mathrm{~m}$ long and $30 \mathrm{~cm}$ wide. Plant to plant spacing was maintained at about $10 \mathrm{~cm}$ by thinning when the seedlings were 20 days old. Fertilizer was applied at the rate of $40: 20: 0 \mathrm{~kg} / \mathrm{ha}$ and all the intercultural operations were adopted as per the package of practices recommended by the Tamil Nadu Agricultural University, Coimbatore. By using barnyard millet descriptors (IPGRI 1983) the data were recorded on five randomly selected plants of each entry of each replication for thirteen yield and yield contributing traits viz., days to $50 \%$

*Author for correspondence: < prakashmscagri@gmail.com>. 


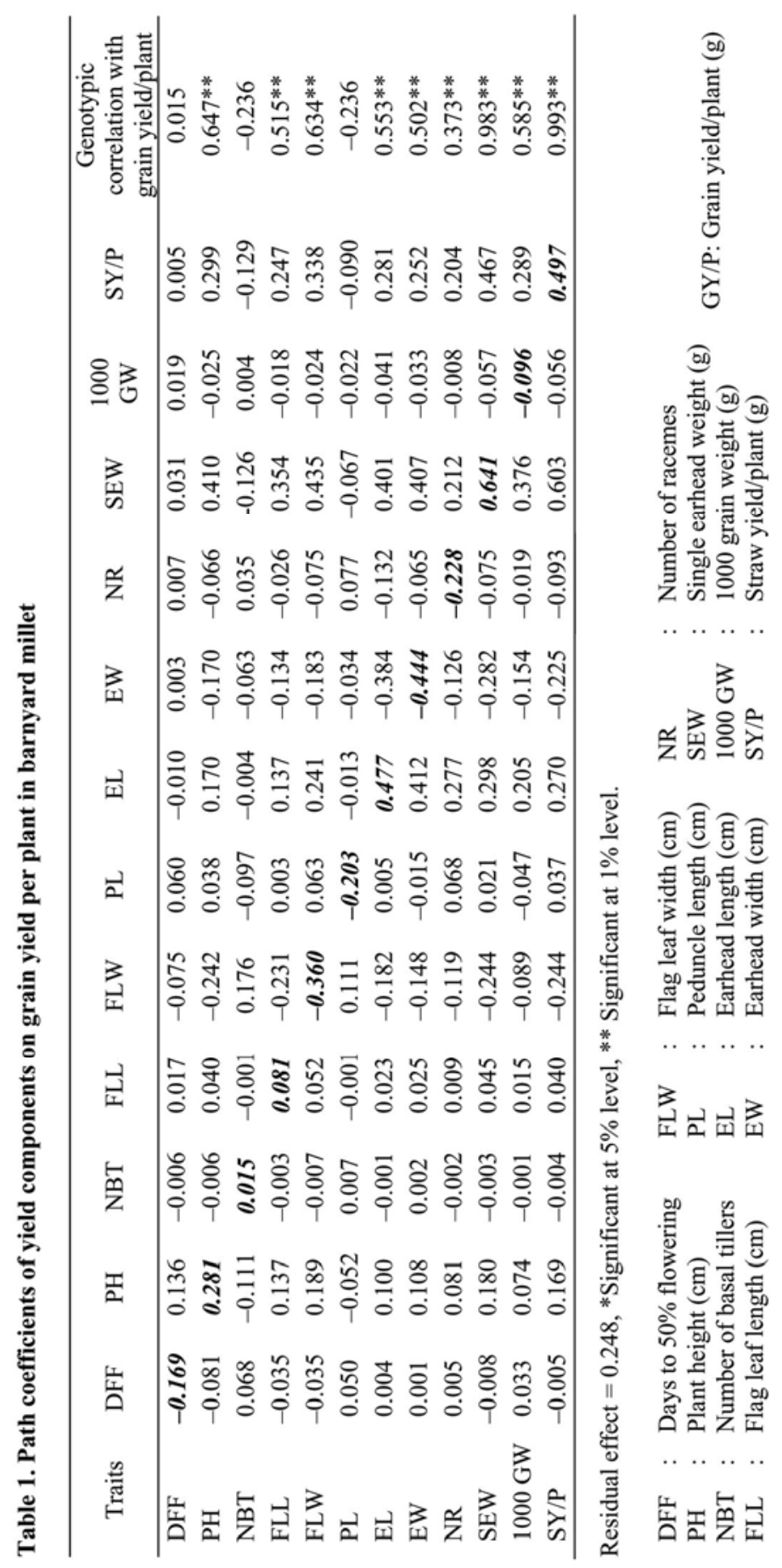


flowering, plant height $(\mathrm{cm})$, no. of basal tillers (no.), flag leaf length $(\mathrm{cm})$, flag leaf width $(\mathrm{cm})$, peduncle length $(\mathrm{cm})$, earhead length $(\mathrm{cm})$, earhead width $(\mathrm{cm})$, no. of racemes, single earhead weight (g), 1000 grain weight (g), straw yield per plant (g) and grain yield per plant (g). Path analysis was determined using genotypic correlations following the technique suggested by Dewey and Lu (1959).

The results on path coefficient analysis are given in Table 1. As observed from correlation study, grain yield per plant was highly significant and positively correlated with straw yield per plant, single earhead weight, plant height, flag leaf width, 1000 grain weight, earhead length, flag leaf length and earhead width. This is in agreement with the reports by Channappagoudar et al. (2008), Arun Gupta et al. (2009), Nirmalakumari and Vetriventhan (2010), Ganesamoorthi (2012) and Prasanna et al. (2013). Results exhibited that single earhead weight had maximum direct effects on grain yield per plant followed by straw yield/plant, earhead length and plant height as also reported by Mohan et al. (2006) and Significant and positive correlation of single earhead weight with grain yield was mainly due to its direct and indirect effects via plant height, earhead length and straw yield/plant. While straw yield per plant exhibited strong positive correlation with grain yield which was mainly due to direct and indirect effects via plant height, earhead length and single earhead weight. Significant and positive correlation of earhead length with grain yield was mainly due to its direct and indirect effects via plant height, single earhead weight and straw yield per plant. The traits plant height had significant and positive correlation with grain yield was mainly due to its direct and indirect effects via earhead length, single earhead weight and straw yield per plant.

Therefore, for the improvement of grain yield in barnyard millet characters like, single earhead weight, straw yield per plant, earhead length and plant height appeared to be the most promising and could be gainfully utilized.

\section{Acknowledgements}

The authors are highly thankful to the University Grants Commission (UGC) for providing necessary funds to carry out this research work and Dr. H.D. Upadhyaya, Principal Scientist and Head Gene Bank, ICRISAT, Hyderabad for providing germplasm seed materials.

\section{References}

Arun G, Mahajan V, Kumar M and Gupta HS 2009. Biodiversity in barnyard millet (Echinochloa frumentacea Link) germplasm in India. Genet. Resour. Crop Evol. 56: 883-889

Channappagoudar BB, Hiremath S, Biradar NR, Koti RV and Bharamagoudar TD 2008. Influence of Morpho - physiological and biochemical traits on the productivity of barnyard millet. Karnataka J. Agric. Sci. 20(3): 477-480.

Dewey DR and Lu KH 1959. A correlation and path coefficient analysis of components of crested wheat grass seed production. Agron. J. 51: 515-518.

Ganesamoorthi M 2012. Genetic variability in barnyard millet [Echnichloa frumentacea (Roxb.) Link.] over different environments. M.Sc Thesis, Agricultural College and Research Institute, TNAU, Madurai, India.

Gopalan C, Ramasastri BV and Balasubramanian SC 2002. Nutritive value of Indian Foods. National Institute of Nutrition, (ICMR), Hyderabad, pp. 47.

IPGRI 1983. Echinochloa millet descriptors. Downloaded from the website address www.bioversityinternational.com/Pulicaiton/pub

Mohan L and Maloo SR 2006. Path coefficient anlaysis for seed yield in barnyard millet millet [Echnichloa frumentacea (roxb.) Link]. Agric. Sci. Digest 26(2): 151-152. 
Nirmalakumari A and Vetriventhan M 2010. Characterization of foxtail millet germplasm collections for yield contributing traits. Electronic J. Plant Breed. 1(2): 140-147.

Prasanna PL, Murthy JSVS, Ram Kumar PV and Rao VS 2013. Studies on correlation and path analysis in Indian genotypes of Italian millet (Setaria italica (L.) Beauv). World Res. J. Plant Breed. 1: 1-4.

(Manuscript received on 24 July, 2013; revised on 11 September, 2013) 